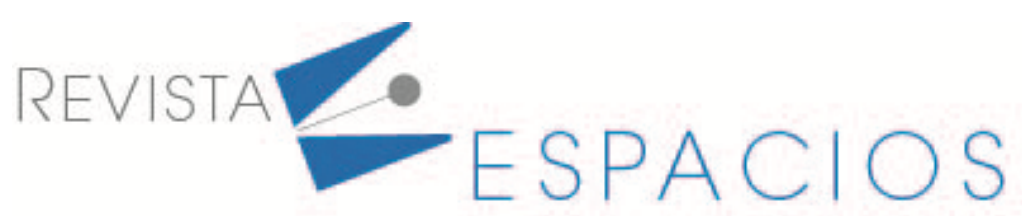

\title{
Gestión del Conocimiento en la transformación de las instituciones educativas desde la TIC
}

\section{Knowledge Management in the transformation of educational institutions from ICT}

\author{
NÁJAR SÁNCHEZ, Olga ${ }^{1}$ \\ MORALES MORGADO, Erla M. ${ }^{2}$ \\ PULIDO HUERTAS, Diana C. ${ }^{3}$
}

\begin{abstract}
Resumen
Las Tecnologías de la Información y la Comunicación (TIC), presentan desafíos y posibilidades en la educación y en la sociedad del conocimiento (SC), requiere profesores con competencias TIC, que gestionen el aprendizaje y el conocimiento. La investigación se centra las TIC y Gestión del Conocimiento (GC) de los profesores, y las competencias TIC de profesores y estudiantes, fortaleciéndolas con prácticas pedagógicas, gestionando y transformando en la SC. La Investigación se trabajó con un estudio de caso exploratorio de tipo cualitativo.
\end{abstract}

Palabras clave: TIC, Gestión del Conocimiento, SECl, Educación

\begin{abstract}
Information and Communication Technologies (ICT), present challenges and possibilities in education and in the knowledge society (KS), require teachers with ICT skills, who manage learning and knowledge. The research focuses on ICT and Knowledge Management (KM) of teachers, and ICT skills of teachers and students, strengthening them with pedagogical practices, managing and transforming them into SC. The research was worked with an exploratory qualitative case study.
\end{abstract}

key words: ICT, Knowledge Management, SECl, Education

\section{Introducción}

La sociedad está cambiando a un ritmo tan acelerado y los sistemas educativos de formación tradicionales no están en la posibilidad de dar respuesta a todas las necesidades de los estudiantes. Para satisfacer estas

\footnotetext{
${ }^{1}$ Estudiante del Doctorado Formación en la Sociedad del Conocimiento, Universidad de Salamanca, España. Profesora de la Licenciatura en Informática y Tecnología, Maestría en Educación y Maestría en Ambientes Educativos Mediados por TIC, programas adscritos a la Facultad Ciencias de la Educación de la Universidad Pedagógica y Tecnológica de Colombia UPTC. Coordinadora del grupo de Investigación Ambientes Virtuales Educativos AVE. Ingeniera de Sistemas Con Énfasis En Software. Especialista en auditoría de sistemas. Especialista en computación para la docencia. Magister en Tecnologías de la Información Aplicadas a La Educación. Candidata a PhD.olga.najar@uptc.edu.co; olga.najar@usal.es. https://orcid.org/0000-0003-1286-7683.

2 Licenciada en Educación. Pedagoga Informática. Magister en Tecnología Educativa. Doctorado en Educación. profesora Contratada Doctora del Departamento de Didáctica, Organización y Métodos de Investigación en la Escuela de Magisterio de Educación y Turismo de Ávila de la Universidad de Salamanca. erla@usal.es. https://orcid.org/0000-0001-5447-8251.

${ }^{3}$ Docente Catedrática de la Universidad Pedagógica y Tecnológica de Colombia UPTC en el programa de Licenciatura en Informática, de la Facultad Ciencias de la Educación, investigadora del grupo Historia de la Educación Latinoamericana HISULA. dianacarolina.pulido@uptc.edu.co. https://orcid.org/00000002-2797-2446
} 
necesidades deben crearse mecanismos para que la educación tenga una mejor cobertura e impacto en el tiempo. En este orden de ideas se planteó, la necesidad de potencializar las habilidades y destrezas de los profesores de la Institución Educativa Gran Colombiano, en el uso y manejo de las Tecnologías de Información y Comunicación (TIC) y mirar las posibles incidencias en la Gestión del Conocimiento (GC).

En la actualidad la educación ha sufrido cambios y transformaciones grandes. La nueva era de la información y la comunicación ha forzado variación en los ambientes rutinarios de aprendizaje caracterizados por la innovación constante. Según el ministerio de TIC de Colombia, en la actualidad son las herramientas fundamentales para la enseñanza, que a los estudiantes les permite lograrán un mejor aprendizaje, y así los profesores al hacer uso de las TIC tienen un óptimo desempeño en sus funciones como formadores, razón por la que se realizó la implementación de las TIC para observar las incidencias que hay en la GC de los profesores y como ellas pueden transmitirlo a los estudiantes en el colegio Gran Colombiano.

Con el fin de incorporar las TIC en los procesos educativos, es necesario entender los tres modelos educativos o de enseñanza que se pueden desarrollar a través de sistemas Learning Management System (LMS) es un sistema informático que soporta ambientes virtuales de aprendizaje para la web y que permiten administrar y documentar lo que incluye en la plataforma Moodle:

1) Transmitir conocimientos,

2) Adquirir, compilar y acumular conocimientos y

3) Desarrollar, inventar y crear conocimientos. (Peter, 2005)

Al examinar las descripciones y las dificultades que debe enfrentar el profesor hoy en día para trabajar en cada uno de estos modelos, se puede señalar que el orden en el que se describen tiene directa relación con lo que hace el profesor cuando comienza a incorporar estas herramientas.

La razón de esta investigación es que se dé la apropiación, uso y aplicabilidad de las TIC en la labor profesor del colegio Gran Colombiano y además mirar si esto influye para que se dé una GC o es todo lo contrario. Para esto se planteó la pregunta de investigación así: ¿Qué incidencias tiene el uso y aplicabilidad de las TIC en la gestión del conocimiento de los profesores de la institución educativa Gran Colombiano?

Luego de esto se propuso, que lo primero que se intenta en el trabajo actual es colocar en las plataformas contenidos en diferentes formatos para sus estudiantes (sólo transmitir conocimientos), luego cuando adquiere algo más de experiencia por parte de los profesores en el manejo de las herramientas del sistema pasa a una segunda etapa, intentando generar interacción entre él y sus estudiantes a través de las opciones del entorno y finalmente poder lograr un manejo técnico y metodológico para usar la plataforma como un ambiente educativo, para inventar y crear conocimiento, teniendo en cuenta que la población de profesores tienen algo de conocimiento y experticia en el manejo de programas informáticos; porque cuando los profesores carecen de estas competencias en el manejo de herramientas informáticas es un poco más complejo que se pueda generar conocimiento a los estudiantes. En el caso de que conozca el manejo de las TIC, lo que primero que debe hacer el profesor es comprobar si las herramientas informáticas si gestionan conocimiento en ellos, y una vez que esto se evidencia, si se puede dar a conocer a los estudiantes.

Es así como el objetivo de este trabajo es investigar si las TIC tienen alguna incidencia en la GC de los profesores, y como podría ayudar a mejorar el proceso de enseñanza y aprendizaje, entre profesores y estudiantes, teniendo en cuenta que en la sociedad del conocimiento, la apropiación y uso de las TIC tienen mayor incidencia sobre todo en la formación de los profesores, quienes son los llamados a y posibilitar procesos activos que generen innovación educativa permanente una eficiente, en el sentido de que se debe innovar y de innovación 
permanente en los procesos de aprendizaje, por lo tanto se debe ser consciente de tener una proyección hacia el futuro, propendiendo por la mejoras sociales y personales en una comunidad académica donde se busca ofrecer una educación de calidad. La investigación se aborda desde lo interpretativo, que toma en cuenta los significados atribuidos por los individuos sujetos de estudio. Como bien lo plantea uno de sus más destacados autores: No existe una realidad social universal válida para todos los hombres, sino que existen múltiples realidades, como múltiples y diversas son las perspectivas con las que los hombres perciben e interpretan los hechos sociales así lo señala (Corbetta: 2007, p. 45). Esta investigación tiene un enfoque cualitativo, el cual es definido por como una intervención sobre la realidad en la que el investigador se abstiene de toda manipulación (...) de esa realidad que estudia en su curso natural.

El tipo de Investigación con el cual se trabajo es un estudio de caso, como una técnica utilizada en la investigación cualitativa. Imaginado como una investigación sobre un individuo, grupo, organización, comunidad o sociedad que es visto y analizado como una entidad (Hernández, 2012). De igual manera según (Maxwell,1998) citado por (Martínez, 2006) es un estudio de caso exploratorio, en la medida en que pretende conseguir un acercamiento entre las teorías inscritas en el marco teórico y la realidad objeto de estudio. A su vez se quiere hacer un acercamiento a una generalización analítica, concebida por (Yin, 1989) como el uso del estudio de caso (...) para ilustrar, representar o generalizar una teoría. Busca representar el caso de manera auténtica en sus propios términos y con la autoridad que es otorgada por quienes son parte del caso. Esta caracterizado como un estudio de caso instrumental, que según (Stake, 2006) citado por (Hernández, 2012) es examinado para proveer insumos de conocimiento a algún tema o problema de investigación, refinar una teoría o aprender a trabajar con otros casos similares. Por el número de casos y unidad de análisis se clasifica según (Yin, 1989) citado por (Hernández, 2012) como estudio de caso holístico, ya que todo el caso es tomado como una sola unidad de análisis (p.8), generado para confirmar, retar o extender una teoría o hipótesis. Es importante resaltar que éste estudio de caso tiene la finalidad de intervención, cuyo propósito es validado por (Arnal, del Rincón, la Torre:1992, p.207) citado por Universidad Internacional de la Rioja.

Para recolección de los datos se implementó el instrumento diario de campo, registrando todo lo que se evidenciaba en el proceso de relación de las TIC con la GC en los profesores de la institución educativa. También se entrevistó a algunos profesores, para conocer sus percepciones sobre los cambios en su proceso de enseñanza y en la GC, luego del proceso realizado en la investigación. El alcance de la investigación se definió como un estudio descriptivo. Busca especificar las propiedades, las características y los perfiles de las personas, grupos, comunidades (...) o cualquier fenómeno que se someta a un análisis (Hernández, 2012).

\subsection{Desarrollo del estudio de caso con las TIC y la Gestión de Conocimiento (GC)}

Utilice esta fuente y espaciado para construir su artículo. En el contexto actual algunos profesores se les dificulta un poco el uso y apropiación de los recursos educativos o material educativo que incorpore TIC, y se observa más en los profesores de básica primaria que laboran en una de las instituciones educativas de la ciudad de Tunja, presentan falencias desde el compromiso y la organización en la cualificación de las necesidades en su formación.

El secretario de educación quien es el que supervisa los proyectos de TIC en Boyacá y "ConVerTIC", es el proyecto de inclusión del Ministerio TIC creado desde el año 2013 con el fin de promover la inclusión social, educativa, laboral y cultural a través de uso de las tecnologías para las personas ciegas o con baja visión, mediante la entrega y masificación del software Jaws y ZoomText. Este expone su punto de vista frente al tema: (E.P, comunicación personal, 8 de julio, 2016): Todo sobre las TIC es un poco complejo para los profesores porque la mayoría de ellos les queda muy poco tiempo para su jubilación, ellos manifiestan no querer incluir dentro de su metodología de enseñanza las herramientas tecnológicas, que eso es tarea de los profesores jóvenes, pero tampoco se interesan por aprender y generar nuevas formas de aprendizaje con metodologías y estrategias diferentes, claro 
que no sucede en todos los casos porque hay algunos profesores que tienen, la motivación, y se proponen aprender a usar las TIC e incorporarlas en sus metodologías.

El secretario de educación departamental, manifiesta que el Ministerio de Educación Nacional de Colombia (MEN) dotó de Tablets y computadores a la mayoría de instituciones de Boyacá, pero el problema en algunos casos no son los recursos, sino la infraestructura con la que todavía no se cuenta para ubicar todos los recursos tecnológicos, y que los profesores se sienten intimidados por sus estudiantes, porque piensan que ellos conocen el manejo de la tecnología mejor que ellos, entonces a la hora de dar sus clases les da un poco de miedo usarlas. De igual forma asegura, que de nada sirve tener salas o talleres bien dotados de tecnología si los profesores no saben utilizarlas y menos implementarlas en el aula de clase.

Los profesores presentes en esta investigación, hoy viven ésta realidad y también expresaron sus preocupaciones (en una conversación personal uno de ellos manifiesta 07/03/2016) que "Las TIC si ayudan a gestionar el conocimiento porque permiten una gran interacción colocando en práctica, la planeación de clase, la metodología del profesor, la herramienta tecnología y al estudiante; claro que siempre y cuando el profesor se apropie y este al corriente de utilizar las TIC", pero realmente para manejar las TIC se necesita tiempo, cualificación con seguimiento y apoyo y no siempre se tiene la disponibilidad ni se cuenta con un seguimiento pertinente en las capacitaciones que ofrecen". El profesor resalta que se debería dar solución a los problemas con los que la mayoría de las instituciones cuentan, la adaptación de la infraestructura para la ubicación correcta de las herramientas tecnológicas y digitales, con buena red de internet y con procesos de cualificación con asesoramiento y seguimiento para que sea provecho, de lo contrario todo esfuerzo sería en vacío.

Por otro lado, para la profesor E. R., mediante conversación personal del 17 de marzo de 2016 expresa que en la mayoría de capacitaciones se ofrecen temáticas que son contenidos asignados por la entidades como alcaldía, gobernación, entre otras y nunca preguntan sobre que les interesaría a los profesores, es importante que se tenga en cuenta las necesidades de quienes se van a capacitar, y se realice un seguimiento de la cualificación para que no quede solo en proyectos o propuestas de corto plazo que luego se pierden y no toman ningún sentido.

Todo esto permite observar que no hay un seguimiento por parte de las entidades para que puedan recoger las inquietudes y sugerencias que proponen los profesores. Alguno de los profesores manifiesta que en algunas ocasiones cuando les van a ofrecer capacitaciones por parte de la alcandía o gobernación, le preguntan las necesidades es al rector, pero a ellos casi que nunca los tienen en cuenta, pero en cuanto a lo referente a las TIC les hablan es de infraestructura, dotación de recursos tecnológicos, son pocas capacitaciones de mínima duración.

Por otra parte, la profesora A.M., expone su punto de vista: (comunicación personal, 5 de abril de 2016), para nadie es un secreto que, para algunos de los profesores, vinculados con el Decreto 2277 de septiembre 24 de 1979. Por el cual se adoptan normas sobre el ejercicio de la profesión profesor, los cuales nos caracterizamos porque nos queda muy poco tiempo de ejercer nuestra profesión y que estamos cerca a pensionarnos, entonces nos preguntamos a estas alturas ¿para qué enseñamos a utilizar la tecnología? Además de que el uso se de las herramientas se nos dificulta y hasta los estudiantes saben manejarlas mejor que nosotras. La institución en ocasiones exige se usen las TIC en el aula con las que cuenta la institución, pero no hay suficientes capacitaciones y las que ofrecen son cortas y sin ningún resultado. Pero quiero resaltar que la cualificación y acompañamiento sobre TIC que hemos estado recibiendo por los profesores quien está ejecutando este proyecto, ha sido de gran ayuda debido a que desde finales de 2014 han estado realizando seguimiento sobre esta temática, una de las profesoras manifestó: "personalmente yo era muy apática a la tecnología pero he logrado con el acompañamiento, tener motivación y buena actitud para aprender", ver las ventajas que nos pueden ofrecer la TIC si le damos un buen uso en la enseñanza, y lo fácil que los estudiantes puede motivarse y aprender con la 
incorporación de diversas herramientas tecnológicas y aplicaciones o programas informáticos. Actualmente se evidencia que es fundamental para aprender el manejo de las TIC, el interés y disposición que el profesor tenga y que la persona que dicte la capacitación tenga paciencia y buena disposición para enseñarnos a los profesores que como yo se nos dificultaba la tecnologías, digo se me dificultaba porque creo que he progresado mucho al igual que varios que mis compañeros ya no necesito de mucha asesoría pues hay cosas que como las practicamos ya no se nos olvidan, claro que el tema de las TIC es muy amplio y un poco complejo por lo tanto seguiremos aprendiendo para poder fortalecer nuestra profesión y para nuestra vida personal puesto que estamos rodeados de tecnología.

Así mismo el profesor (F. R., comunicación personal, 5 de abril de 2016) dice que en ocasiones el manejo de los recursos que tienen en la institución son limitados, debido a que no hay conocimiento a fondo de ello. Las voces de los profesores aquí presentadas, son profesores de básica primaria de una institución educativa de Tunja, de edades entre los 29 a 60 años, encargados de orientar todas las áreas en el grado que tienen a su cargo entre estas el área de Tecnología e Informática. Muchos de los profesores soy Licenciados en Ciencias Sociales, Matemáticas, Ciencias Naturales, Filosofía, Educación física y de Básica Primaria.

Cabe resaltar que al iniciar la propuesta de esta investigación fue un poco difícil porque aunque el señor rector y la coordinadora colaboraron organizando un cronograma en el que se desarrollaría el trabajo de campo, algunos de los profesores no querían saber del manejo de recursos tecnológicos e informáticos debido a que en años anteriores les habían hecho dos capacitaciones sin tener ningún resultado y algunos con rechazo total a las tecnologías, por lo tanto se debió iniciar con mostrarles las ventajas de aprender a usarlas y se apropiaran de la tecnología no solo les serviría para su quehacer profesor sino para su vida personal como el manejo de su celular y trámites que se pueden hacer en línea, para luego si mostrarles cómo podían utilizarlas el aula de clase.

Para tener una visión más amplia del contexto actual de los profesores, se realiza una entrevista a tres estudiantes que reciben clases con algunos de estos maestros. La información que dan los estudiantes, permite evidenciar que los profesores no incorporan es sus clases las tecnologías, que las han utilizado pocas veces, pero es por alguna practicante (estudiantes de último semestre de Licenciatura) que llegue al colegio o por que la profesor que contratan para dar la clase de informática y tecnología y que los lleva a la sala de informática.

(Estudiantes, comunicación personal, 6 de marzo de 2015) el ideal de los estudiantes es que a pesar de que su profesor intenta enseñarle la temática lo más clara posible, pero hay ocasiones que es mucha teoría y no logran entender la temática. Ellos les gustaría que los profesores utilizaran los recursos tecnológicos con los que cuenta la institución como son tablets, portátiles, PC, Video Beams; en muy pocas ocasiones intentan algunos profesores usarlas, pero se sienten un poco inseguros. Los estudiantes creen que hay temáticas del uso de las TIC que ellos conocen un poco más que los algunos de los profesores, por lo tanto, les gustaría que sus profesores se preparan más en la utilización de la tecnología para que la puedan usar en sus clases y facilitar que los estudiantes aprendan de una forma más rápida aprovechando que se nos facilita la tecnología y nos gusta usarla en nuestro entorno y mucho más en clase.

A pesar de que los estudiantes tienen un gusto por el manejo de TIC, les parece adecuado el trabajo de memorización y clase tradicional de sus profesores, aunque no niegan que en ocasiones se torne aburrido. Aseguran que si no están vigilándolos o no se preparó una clase donde estén todo el tiempo ocupados se forma desorden, al igual si la clase es con uso de TIC entre ellas, alguna aplicación informática y no se dan las instrucciones claras, los estudiantes entran a otras páginas o se distraen en otras distintas a la finalidad de la clase, por eso de la importancia de sus profesores conozcan el uso y se apropien de la utilización de las TIC para que las clases tengan el sentido de enseñanza y aprendizaje. 
Además, algunos profesores han participado en programas como "TIC en Boyacá", y" ConVerTIC", capacitaciones realizadas en convenio de la Secretaría de Educación y la Gobernación, pero aseguran que han sido muy cortas y han dejado varias inquietudes que no les permiten el aprovechamiento posterior de lo aprendido y no recuerdan el haberse tenido en cuenta sus necesidades, para responder a las problemáticas que se presentan en el campo de la tecnología e informática.

De las principales necesidades que los profesores de la institución pública donde se llevó a cabo la investigación, presentan en cuanto a las TIC, es el uso y apropiación de dispositivos como la Tablet, y que para ellos es preocupante contar con una buena cantidad de este tipo de recursos y saber que uso pedagógico se le puede dar o como llevarlas al salón de clase sin que se convierta en un dolor de cabeza para ellos, a pesar de que la institución no lleva un registro o seguimiento del uso de estos recursos, sino que el profesor que las quiera utilizar puede solicitarlas a la coordinadora, algunos profesores están interesados en empezar a darles un uso adecuado en sus clases que puedan generar transformación a sus formas tradicionales de enseñar, para lo cual es fundamental que se adquiera una habilidad en recursos TIC, logrando así que el profesor logre gestionar su conocimiento con la apropiación de estos recursos.

Por otra parte, otro profesor manifiestan que el problema en algunas ocasiones además de lo expuesto por sus demás compañeros es el tiempo porque ellos tienen otras actividades institucionales, como diligenciar formatos, planillas, hacer seguimiento a los estudiantes para que ninguno pierda el año escolar, entre otras está el hecho de hacer los trámites y llenar formatos de préstamo de implementos (recurso tecnológicos) le quita tiempo, por lo tanto prefiere no utilizarlas además aclaran de que conocen muy poco del manejo ya que en su época de estudiante no utilizo nada parecido a un recurso informático. Por lo tanto, los únicos recursos establecidos para la labor del profesor con sus estudiantes son el tablero, el cuaderno y guías-taller. Mientras los portátiles, Tables, video beam y PC, y otros recursos reposan en un aula con llave, siendo el aula de informática la única utilizada en ocasiones por el/la profesor que contratan para dar la clase de informática y tecnología.

\section{Metodología}

\subsection{Paradigma y enfoque de Investigación}

El paradigma con el cual se lleva a cabo esta investigación es el interpretativo, que toma en cuenta los significados atribuidos por los individuos sujetos de estudio. Como bien lo plantea uno de sus más destacados autores: "No existe una realidad social universal válida para todos los hombres, sino que existen múltiples realidades, como múltiples y diversas son las perspectivas con las que los hombres perciben e interpretan los hechos sociales" (Corbeta, 2007, p.26). Éste paradigma esta completamente ligado al enfoque cualitativo, el cual es definido por Corbeta 2007 como una intervención sobre la realidad en la que el investigador se abstiene de toda manipulación (...) de esa realidad que estudia en su curso natural" ( p. 45). El mismo autor.

Para recolectar los datos se uso diario de campo donde se resgistro todo lo que se evidenciaba en el proceso de relación de las TIC con la Gestión de Conocimiento en los profesores de la institución educativa. También se entrevisto a algunos profesores, para conocer sus percepciones sobre los cambios en su proceso de enseñanza y en la gestión del conocimiento luego del proceso realizado en la investigación.

\subsection{Tipo de Investigación}

Se plantea un Estudio de Caso, como una técnica utilizada en la investigación cualitativa. Imaginado como una investigación sobre un individuo, grupo, organización, comunidad o sociedad que es visto y analizado como una entidad (Hernandez, 2012, p.1). De igual manera según Maxwel 1998 (citado por Martinez, 2006) es un estudio de caso exploratorio, en la medida en que pretende conseguir un acercamiento entre las teorías inscritas en el marco teórico y la realidad objeto de estudio. A su vez se quiere hacer un acercamiento a una generalización 
analítica, concebida por Yin 1989, como el uso del estudio de caso (...) para ilustrar, representar o generalizar una teoría. Busca representar el caso de manera autentica en sus propios términos y con la autoridad que es otorgada por quienes son parte del caso. Es caracterizado en la categoria de estudio de caso instrumental, que según (Stake, 2006) (citado por Hernández, 2012) es examinado para proveer insumos de conocimiento a algún tema o problema de investigación, refinar una teoría o aprender a trabajar con otros casos similares. Por el número de casos y unidad de análisis se clasifica según Yin 2009 (citado por Hernadez, 2012) como estudio de caso holístico,ya que todo el caso es tomado como una sola unidad de análisis (p.8), generado para confirmar, retar o extender una teoría o hipótesis. Es importante resaltar que éste estudio de caso tiene la finalidad de intervención, cuyo propósito es válidado por (Arnal, del Rincon yla Torre, 1992, p.207 (citado por Universidad Internacional de la Rioja, s.f, p.9).

El alcance de la investigación se define como un estudio descriptivo. "Busca especificar las propiedades, las características y los perfiles de las personas, grupos, comunidades (...) o cualquier fenómeno que se someta a un análisis" (Hernández, 2010, p.80).

\section{Población Muestra}

Una institución educativa publica de la ciudad de Tunja, cuenta con 52 profesores de aula de los cuales 17 dictan en clase en básica primaria. Por lo tanto, la población tomada para la ejecución de esta investigación está. Quienes solicitan recibir acompañamiento en el manejo de las TIC, debido a que las cualificaciones que se les han dado sobre este tema han dejado varios vacíos y han sido muy pocas, además de no asumirse compromiso y motivación frente al desarrollo de estas competencias, para la muestra se toman ocho, seleccionándolos al azar.

\section{Fuentes e instrumentos}

Como fuentes primarias, se trabajó con siete profesores de la institución educativa Gimnasio Gran Colombiano de la ciudad de Tunja. Los criterios metodológicos son básicamente el interés del colegio y de algunos profesores participan en esta investigación, bajo el argumento y con la necesidad que presentan en el campo de las tecnologías de la Información y la comunicación (TIC). La coordinadora manifiesta el deseo que sus profesores puedan representar a la institución y participar en proyectos que tengan que ver con tecnología o informática en programas que ofrece el Ministerio de TIC o la misma Gobernación de Boyacá.

Los profesores son fuentes de información primordial, no sólo porque están en el rango dispuesto para la población objeto de estudio, sino que además no cuentan con formación en TIC no poseen los conocimientos ni preparación en este campo, hay muchos de ellos que tienen la motivación y quieren gestionar y transformar su conocimiento y el de sus niños y aportar a la investigación. El trabajar con los profesores, permitió que se obtuvieran criterios y argumentos muy importantes en la incorporación y uso de las tecnologías en el proceso enseñanza y aprendizaje para la obtención de alguna información para la gestión de conocimiento.

Otra de las fuentes primaria para el desarrollo del estudio son los estudiantes, la mirada de ellos es fundamental en el reconocimiento del panorama actual que se está dando en las instituciones con los profesores frente al tema de la incorporación y uso de las TIC y como estas influyen en la gestión del conocimiento. Los criterios de selección se desglosan básicamente de tomar 3 estudiantes de grado cuarto y quinto que recibieran clases de algunos de los profesores participantes.

Las Fuentes Secundarias, entre estas se encuentran libros y bases de datos de reconocimiento científico que cuentan con información confiable y actualizada y revisada de forma pertinente por el personal correspondiente para tal fin y que en su mayoría son trabajadas de instituciones de educación superior reconocidas (políticas, Planes de Gobierno y demás literatura). 


\section{Resultados}

El proceso para la recolección de información se da en tres fases. En un primera se aplican un instrumento que permite recoger un diagnóstico de las debilidades TIC en los profesores, el conocimiento que tienen sobre gestión de conocimiento y el uso más frecuente que le dan respecto a las TIC. Luego se da una fase de cualificación a los profesores sobre el uso y manejo de las TIC, en este mismo proceso se hace acompañamiento antes y durante algunas clases dando asesoría cuando el profesor lo solicitara y finalmente se realiza la fase de observación, contraste y análisis.

\subsection{Fase Uno: Diagnóstico}

Como primera medida se estructura y se elabora el instrumento encuesta a utilizar como diagnóstico a los profesores (encuesta para profesores), dentro esta fase también se realizó una entrevista semi estructurada como una opción para abordar asuntos o temas en los cuales tal vez no se piensa que pueda surgir de las respuestas de los entrevistados. Es una guía de asuntos o preguntas, en la que el entrevistador tiene la libertad de introducir preguntas adicionales para precisar conceptos u obtener mayor información sobre los temas deseados (Hernández: 2010, p. 480).

Una de las entrevistas se realizó a estudiantes de los grados cuarto y quinto de básica primaria de la institución oficial de Tunja, el fin del instrumento es conocer más sobre el uso que los profesores les dan a las TIC, unas de las preguntas que se realizan en las entrevistas son: ¿en qué asignaturas sus profesores utilizan recursos Tecnológicos o informáticos? ¿Qué tipo de actividades realizan con apoyo de éstas?, ¿qué tipo de recursos utilizan?, ¿Cómo cree que el profesor se desenvuelve con el apoyo de los recursos informáticos? Esto con la finalidad de conocer si existe la necesidad de que los profesores conozcan el manejo y uso de las TIC para la implementación en el aula, o si efectivamente se está dando una transformación educativa con el uso de estos recursos.

Además de realizar la encuesta a profesores y entrevistar a estudiantes también se quiso realizar una a las personas encargadas de los diferentes programas que ofrece la secretaria y la gobernación para el manejo de las TIC. Para lo cual se elaboran una entrevista que evidencie la importancia que les dan a las competencias TIC para profesores, las preguntas que se realizaron. ¿Con qué programas se cuentan para la enseñanza de manejo de recurso tecnológico e informático en las instituciones educativas? ¿Cómo se formula la temática en la que se da la cualificación? ¿Qué perspectiva se tiene del compromiso del profesor en estas cualificaciones? ¿Qué duración tiene la mayoría de capacitaciones que se ofrecen sobre estos temas? ¿Cómo es la participación de los profesores en dichas capacitaciones? y ¿Cómo se da proceso de gestión de conocimiento en la cualificación para las instituciones educativas?

Esto con el fin de tener diversas miradas y puntos de vista de las personas quienes están involucradas en el fortalecimiento de las competencias TIC. En este aspecto se aplica la entrevista a: el secretario de educación y el jefe de planeación, quienes aportan significativamente sobre la ejecución de las cualificaciones que les ofrecen a través de algunos programas a las instituciones educativas.

En esta fase se puede concluir que los resultados de la encuesta y de las entrevistas realizadas. La mayoría de los profesores no conocen sobre el manejo de las TIC ni cómo implementar en sus clases, eso también lo afirman los estudiantes cuando mencionan que los profesores no utilizan en las clases ninguna herramienta informática y cuando alguno intenta utilizarla lo hace con temor porque sienten que ellos manejan mejor las herramientas que ellos, por lo que le piden colaboración al estudiante que tenga mayor conocimiento en manejo de estas.

Por otra parte, los personas encargadas de liderar varios de los programas sobre las TIC en las entidades como secretaria de Educación y gobernación, manifiestan que los programas que manejan cuentan con algunas 
campañas de capacitación sobre esta temática, sino que no hay compromiso y motivación por parte de los profesor y pues manifiestan que tal vez si una de las fallas es que los cursos son de corta duración y no se realiza ningún seguimiento del proceso, además de que pocas veces se tiene encuentra al profesor para que determine la temática en la que se quiere cualificar, si no que el rector es que toma la decisión y ellos dan por entendido que la consulto con sus profesores.

\subsection{Fase Dos: Cualificación y acompañamiento}

Se inicia realizando un proceso de cualificación y acompañamiento con el propósito de poder realizar un seguimiento profundo con cada uno de los profesores. Para iniciar el proceso de cualificación se dio una charla dirigida por la profesora Olga Nájar Sánchez sobre la importancia de implementar las TIC en el quehacer profesor y sobre que es GC, luego se cualifico a los profesores primero de forma grupal y enseguida individual, se elaboró un manual sobre el manejo de tabletas y con ayuda de los profesores se trabajó una lista de aplicaciones educativas por áreas que se podrían trabajar con los estudiantes, también se enseñó a trabajar algunos programas como prezi, virtualdub ( editor de videos), Cmaptools( mapas conceptuales), voki (avatar) y aulas virtuales gratuitas entre esta la plataforma Edmodo. Allí se crea un curso con los profesores y se trabajan algunas temáticas virtuales sobre las TIC.

En el acompañamiento individual, el profesor realizó la planeación de su clase, en ocasiones él no sabe que aplicación podría utilizar y ahí es donde se interviene sugiriéndole donde puede encontrar algunas o recomendándole aplicaciones que podría utilizar dependiendo la asignatura y el tema, pero la mayoría de profesores donde necesitan el acompañamiento es en el desarrollo de su clase, porque aunque hay practica antes de ejecutarla en el aula, en ocasiones tenían problemas, la tableta se bloquea porque el estudiante le dio otra instrucción y ya no encuentra la aplicación entre otras, por lo tanto, en ese momento se intervenía para darle la respectivas instrucciones y que el profesor mismo solucionara el problema, para que así el supiera cómo debía proceder si volvía a suceder.

Finalizando esta fase se aplicó una entrevista a los profesores, para conocer expectativas, y cambios que han tenido durante el proceso y en qué nivel están luego de pasar este proceso, no sólo en su contexto educativo sino además en su hogar, en sus relaciones sociales y diario vivir. Se hacen preguntas como: ¿Qué tipos de herramientas tecnológicas e informáticas maneja? ¿Cuáles son las fortalezas con las que cuenta en este campo?, ¿Cuáles suponen han sido las fortalezas y debilidades en las cualificaciones profesores en las que han participado? ¿Qué actividades realizan ahora con apoyo de las TIC?, ¿Cuál es la experiencia de utilizar las TIC?, ¿Qué diferencias observa al utilizar las TIC en sus clases cuando no hace uso de ellas? Y ¿Qué debilidades cree que aún posee en el manejo de las TIC?. Estas preguntas intentan establecer si los profesores si se apropiaron del uso de estos recursos y si hay gestión de su conocimiento como lo realizan.

El proceso de acompañamiento se apoya con la técnica para recolección de datos "Observación Participante", la cual fortalece su implementación en el hecho de poder acercarse a la realidad del objeto de estudio y enriquecer la información con experiencias, expresiones y formas de actuar de los sujetos investigados. Esta técnica facilita un panorama de las inquietudes de los profesores frente a su aprendizaje: ¿cómo perciben el proceso?, ¿Qué necesidades tienen a la hora de aprender?, ¿qué factores los motivan y cuales los desmotivan a la hora de cualificarse? y otros aspectos que sin duda deben ser conocidos por los gestores de políticas y cualificaciones. En esta fase se puede concluir, que, aunque hay profesores que inicialmente opusieron resistencia a la cualificación y no querían saber nada sobre las TIC, y dando miles de escusas, pero que a raíz de ir hablando con ellos y motivándolos se fueron incorporando en el proceso. Asimismo, hay profesores entusiasmados por aprender porque deseaban implementar el uso de nuevas herramientas en sus clases. 
De los 17 profesores tres conocían el manejo del paquete de office que trae las tablets y manejo de cámara, los demás se les dificultaba, y 14 de los profesores maneja lo básico de word y power point del paquete de office de la computadora. Los profesores mencionan que de los procesos de cualificación que han tenido por parte de la secretaria, no han adquirido muchos conocimientos, debido a que en algunas situaciones son ellos los que no asisten porque no son en jornadas no laborales y ellos deben hacer sus cosas personales, en otros casos ellos inician el curso, pero este se torna complejo y el instructor sigue con los que entienden y ellos se sienten perdidos y por lo tanto dejan de asistir, además la mayoría de capacitaciones son demasiado cortas para lograr aprender a manejar varios programas y por ultimo manifiestan que se sienten indignados porque no les tienen en cuenta la opinión sobre lo que les gustaría aprender y han tenido la experiencia que han asistido a cualificaciones de manejo de herramientas tecnológicas y el internet no funciona y se queda el instructor es tratando de resolver los problemas de conectividad y no se alcanza a explicar mucho y al final les entregan una memoria con aplicaciones y programas para que los utilicen, pero no saben cómo instalarlos.

Por lo tanto, con esta cualificación y acompañamiento se quiere que al finalizar los profesores lograron la manipulación, en especial de dispositivo móvil (Tablets) en términos de configuración, descarga e instalación y manejo de aplicaciones y que pudieran incluirlas en sus labores diarias tanto en la parte laboral como personal. (Ver Tabla 3 y 4 ).

Después de haber realizado el proceso de cualificación en competencias digitales con los profesores y de acotar algunas observaciones de cómo se aplicaban las competencias digitales, en su aula de clase, se puedo concluir que si existen las competencias digitales y que estas pueden ser adquiridas por los profesores. En este caso se logró que los profesores adquirieran habilidades en acceder a la información y algunos de ellos alcanzaron competencias en su totalidad que luego fueron trabajadas con los estudiantes.

Se trabajó con profesores las habilidades instrumentales por medio del desarrollo de actividades para que, a través de las distintas tecnologías o herramientas tecnológicas como las tabletas, puedan utilizarlas para localizar información útil para sus propósitos, que le ayude a resolver problemas y crear actividades, ejercicios, talleres. Según (Márquez, 2008) el profesor que posee competencias digitales además de localizar la información tiene la capacidad de transformar la información en conocimiento, es decir ser capaz de plantear problemas, analizar e interpretar con significado la información utilizando los diferentes programas o aplicaciones educativos que ofrece la red. Según lo que se logró observar en el proceso de cualificación es importante destacar las enormes posibilidades de las tabletas en un entorno de clase como recurso de aprendizaje por su versatilidad, portabilidad funcionalidad y el acceso a diversos materiales educativos.

\subsection{Fase Tres: Observación. Diarios de Campo}

Cuando ya se termina la fase de cualificación y acompañamiento se procede a realizar la observación esta se llevó a cabo durante un periodo de 6 meses (15 de febrero al 29 de julio de 2016), en los cuales el investigador no interviene en nada solo se limita a observar y la recolección de la información de las observaciones se realiza mediante diarios de campo, videos y fotografías. Además, en esta fase se observa el seguimiento al modelo SECI (Socialización, Externalización, Combinación e Internalización).

La socialización, se realiza cuando los profesores interactúan con los estudiantes y de igual forma logran interactuar a través de video conferencias, donde utilizan la cámara e implementan herramientas de la realidad virtual, esto se hace cuando los profesores proponen a los estudiantes realizar talleres y cada uno lo realiza de manera individual, generando conocimiento individual. Es decir, cada uno tiene su propio conocimiento y es a lo que se identifica como conocimiento tácito.

En la Externalización se genera conocimiento grupal, porque los estudiantes trabajan a través de plataformas virtuales como lo es Moodle y logran tener conocimiento por lo menos de que existen algunos sistemas expertos, que hay proceso de simulación y lo buscan a través de las redes de comunidades académicas que logran conocer 
por parte de sus profesores, y a la vez ya tienen más herramientas TIC que les permite generar habilidades de rastreo para poderse comunicar y una de ellas ha sido la tecnológica móvil. Aquí el conocimiento tácito se pasa a conocimiento explicito, porque comienza a socializarse de alguna manera con herramientas TIC (Ver Tabla 1.).

Otra de las partes interesantes en el desarrollo del modelo $\mathrm{SECl}$, es la internalización, donde a través de las redes de comunidades se logra compartir el conocimiento deforma grupal e individual y a la vez se compara con lo que se transmite y comunica, como es la información que se encuentra en las bases de datos bibliográficas, en bases de datos corporativas, en las redes de conocimiento colectivo y los grupos de trabajo que se conforman para poder hacer trabajo compartido. El conocimiento cuando se socializa, y se comparte, se vuelve explicito, cada uno de los estudiantes lo comienza a interiorizar para apropiarse de él y empoderarse de ese conocimiento compartido de forma colectiva.

Figura 1

Modelo SECI

\begin{tabular}{|c|c|}
\hline \begin{aligned} & Socialiación \\
Tácito $->\mathrm{T}$ ácito & \multicolumn{1}{c}{ Comunicación cara a cara } \\
$> &$ VideoConferencias \\
$> &$ Webcams \\
$> &$ Herramientas de realidad Virtual \end{aligned} & \begin{tabular}{ll} 
& \multicolumn{2}{c}{ Externalización } \\
Tácito $->$ Explicito \\
$>\quad$ Herramientas para captar procesos \\
$>\quad$ Habilidad de ras treo \\
$>\quad$ Redes de iguales \\
$>\quad$ Sistemas expertos \\
$>\quad$ Plataforma de Discusión.
\end{tabular} \\
\hline $\begin{array}{cc} & \text { Internalización } \\
& \text { Explicito } \rightarrow \text { Tácito } \\
> & \text { Redes de Conocimiento Colectivo } \\
> & \text { Bases de Datos/memoria corporativa } \\
> & \text { Reconocimiento de patrones } \\
> & \text { Redes de Trabai }\end{array}$ & 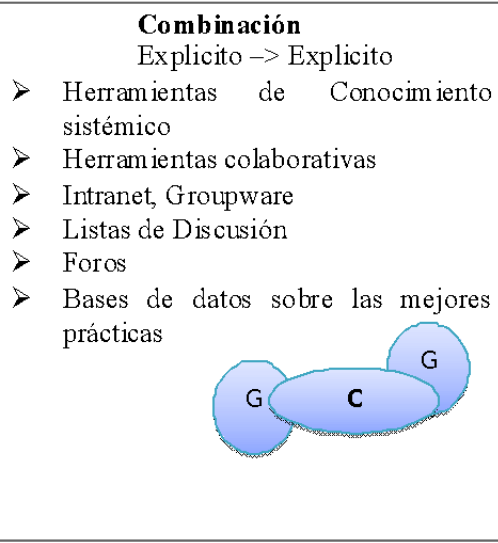 \\
\hline
\end{tabular}

Fuente: Las autoras

En relación a la combinación, consiste en el conocimiento de herramientas TIC (Ver Tabla 2) de conocimiento las cuales adoptan los profesores y los estudiantes y que se vuelven herramientas colaborativas para trabajar en equipos de manera colaborativa en forma grupal a través de herramientas de comunicación como lo puede ser los foros, los chats, los wikis, que permiten trabajar de manera sincrónica, y asincrónica, y a través de ellas por ejemplo los foros se pueden generar discusiones, y debate y procesos de reflexión alrededor de temáticas propuestas por el profesor y por los estudiantes. Es así que el conocimiento explicito, se da a conocer en las redes de comunidades académicas, o las redes de aprendizaje.

Luego de tener toda la información se procede a realizar el análisis de datos el cual se hace mediante el apoyo de los paquetes estadísticos como SPSS para el caso de la encuesta, que evalúa el nivel del uso de las TIC por parte de los profesores y ATLAS TI para el caso de análisis de entrevistas.

La respuesta a algunas preguntas de la encuesta diagnóstico que se le realizó a los profesores fue: 
Tabla 1

Utiliza las TIC para aprender por iniciativa personal y para actualizar los conocimientos y prácticas propios de su disciplina

\begin{tabular}{|c|c|c|c|c|c|}
\hline Válido & & 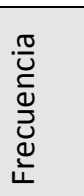 & $\begin{array}{l}\frac{0}{\frac{0}{\pi}} \\
\stackrel{0}{0} \\
\frac{0}{0} \\
0\end{array}$ & 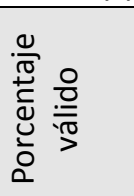 & 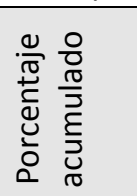 \\
\hline & $\mathrm{NO}$ & 4 & 22,2 & 22,2 & 22,2 \\
\hline & SI & 12 & 66,7 & 66,7 & 88,9 \\
\hline & $\begin{array}{l}\text { ALGUNAS } \\
\text { VECES }\end{array}$ & 2 & 11,1 & 11,1 & 100,0 \\
\hline & Total & 18 & 100,0 & 100,0 & \\
\hline
\end{tabular}

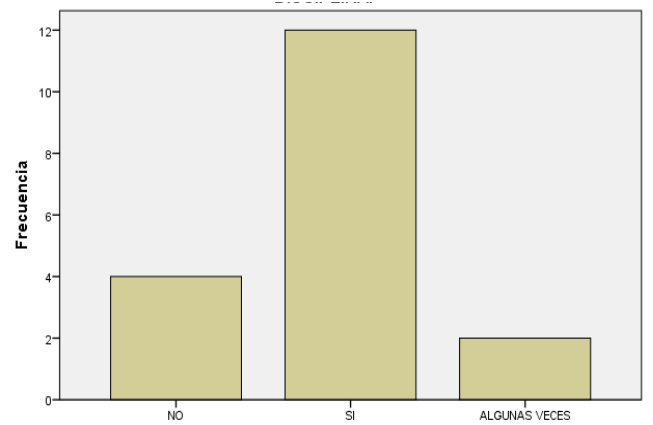

En respuesta a esta pregunta se observa que los profesores tienen el interés de utilizar las TIC y manifiestan en la respuesta que algunos las utilizan, pero al preguntarles como las utilizan, manifiestan que haciendo consultas en internet sobre la temática que desean.

Tabla 2

Utiliza TIC con sus estudiantes para atender sus necesidades e intereses y proponer soluciones a problemas de aprendizaje.

\begin{tabular}{|c|c|c|c|c|}
\hline \multicolumn{5}{|l|}{ Válido } \\
\hline & 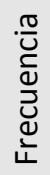 & $\begin{array}{l}\frac{0}{\pi} \\
\stackrel{0}{0} \\
\frac{0}{0} \\
\frac{0}{0}\end{array}$ & 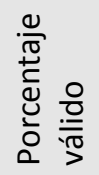 & 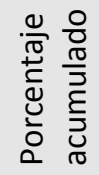 \\
\hline $\mathrm{NO}$ & 8 & 44,4 & 44,4 & 44,4 \\
\hline SI & 4 & 22,2 & 22,2 & 66,7 \\
\hline $\begin{array}{l}\text { ALGUNAS } \\
\text { VECES }\end{array}$ & 6 & 33,3 & 33,3 & 100,0 \\
\hline Total & 18 & 100,0 & 100,0 & \\
\hline
\end{tabular}

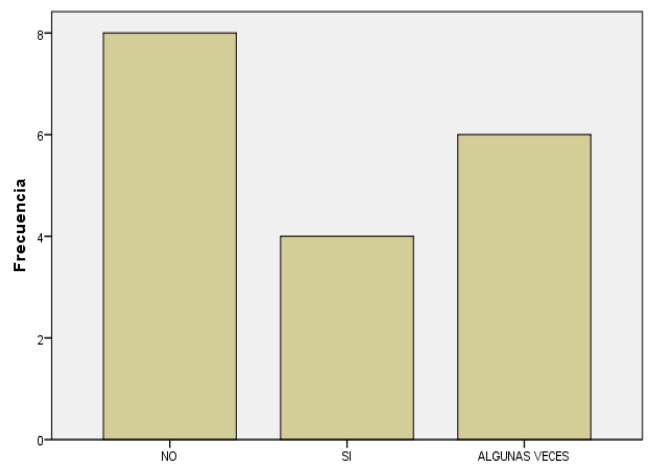

A esta pregunta los profesores manifiestan que no utilizan ningún recurso tecnológico ni informático con los estudiantes y seis solo algunas veces y 4 las utilizan, pero al hablar con los profesores que herramientas TIC utilizan ellos contestan que el video Beam para presentar algún video.

Tabla 3

Usted, desearía integrar más las

TIC en sus asignaturas que orienta

\begin{tabular}{|c|c|c|c|c|}
\hline Válido & 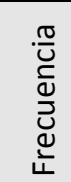 & $\begin{array}{l}\frac{0}{\pi} \\
\stackrel{0}{0} \\
\frac{0}{0} \\
0\end{array}$ & 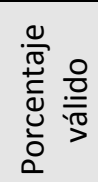 & 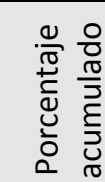 \\
\hline $\mathrm{SI}$ & 18 & 100,0 & 100,0 & 100,0 \\
\hline
\end{tabular}

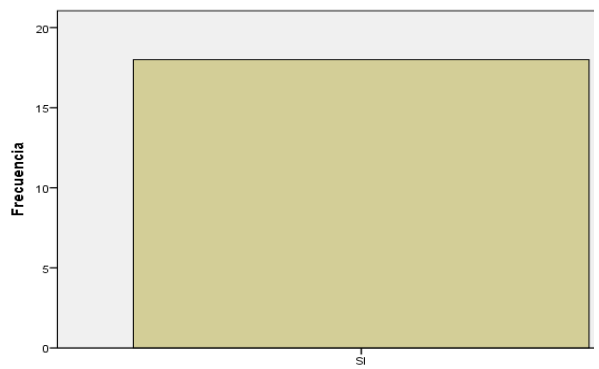

En la respuesta a esta tercera pregunta todos coinciden que el uso de las TIC en el aula va a generar grandes cambios en su metodología y por lo tanto el proceso de enseñanza y aprendizaje cambiaria. En cuanto a la creación de actividades por parte de los profesores, las posibilidades son ilimitadas, desde ejercicios de respuesta múltiple, respuesta corta, actividades de tipo tormenta de ideas, ejercicios de psicomotricidad en estudiantes de 
corta edad o con necesidades educativas específicas, señalar sobre una imagen la parte que corresponda al contenido que se está tratando, seguir instrucciones para completar un gráfico o un diagrama, entre otros. Esto se trata de las múltiples estrategias que permiten no sólo al profesor enviar contenidos y corregir actividades, sino que también a los estudiantes pudieron interactuar en las correcciones o presentar contenidos multimedia al resto de sus compañeros en clase.

Tabla 4

Caracterización del

manejo de tabletas

\begin{tabular}{|c|c|c|}
\hline Sujeto & Elementos de la tableta que maneja & $\begin{array}{c}\text { Elementos de la } \\
\text { tableta que carece }\end{array}$ \\
\hline 1 & $\begin{array}{l}\text { Manejo básico de la interfaz externa de la tableta. } \\
\text { Maneja el procesador de texto } \\
\text { Usa el correo electrónico para enviar y recibir correos. } \\
\text { Navega por internet para hacer consultas. } \\
\text { Captura imágenes. } \\
\text { Descarga aplicaciones en la tableta y con ejercicios las aprende a manejar al punto de crear } \\
\text { actividades de enseñanza. } \\
\text { Pasa archivos de la tableta a la memoria usb o de la memoria usb a la tableta }\end{array}$ & No maneja la hoja de cálculo. \\
\hline 2 & $\begin{array}{l}\text { Manejo de la interfaz externa e interna de la tableta. } \\
\text { Maneja el procesador de texto y aplicaciones como power point y powtoon para realizar } \\
\text { presentaciones para sustentar o dar a conocer un tema. } \\
\text { Manejo del correo electrónico. } \\
\text { Descarga aplicaciones en la tableta y prepara talleres para trabajar con los estudiantes. } \\
\text { Editar imágenes o fotografías. } \\
\text { Navega por internet para hacer consultas. } \\
\text { Pasa archivos de la tableta a la memoria usb o de la memoria usb a la tableta. }\end{array}$ & Ninguna \\
\hline 3 & $\begin{array}{l}\text { Manejo de la interfaz externa e interna de la tableta. } \\
\text { Maneja el procesador de texto, hoja de cálculo y aplicaciones como power point y powtoon } \\
\text { para realizar presentaciones para sustentar o dar a conocer un tema. } \\
\text { Manejo del correo electrónico. } \\
\text { Editar imágenes o fotografías. } \\
\text { Navega por internet para hacer consultas. } \\
\text { Pasa archivos de la tableta a la memoria usb o de la memoria usb a la tableta. }\end{array}$ & $\begin{array}{l}\text { Descarga de aplicaciones en } \\
\text { la tableta. }\end{array}$ \\
\hline 4 & $\begin{array}{l}\text { Manejo básico de la interfaz externa de la tableta. } \\
\text { Maneja el procesador de texto } \\
\text { Usa el correo electrónico para enviar y recibir correos. } \\
\text { Navega por internet para hacer consultas. } \\
\text { Captura imágenes. } \\
\text { Descarga aplicaciones en la tableta y con ejercicios las aprende a manejar al punto de crear } \\
\text { actividades de enseñanza. } \\
\text { Editar imágenes o fotografías. }\end{array}$ & $\begin{array}{l}\text { Se le dificulta pasar archivos } \\
\text { de la tableta a la memoria } \\
\text { usb o de la memoria usb a la } \\
\text { tableta. }\end{array}$ \\
\hline 5 & $\begin{array}{l}\text { Manejo de la interfaz externa e interna de la tableta. } \\
\text { Maneja el procesador de texto y aplicaciones como power point y powtoon para realizar } \\
\text { presentaciones para sustentar o dar a conocer un tema. } \\
\text { Manejo del correo electrónico. } \\
\text { Navega por internet para hacer consultas. } \\
\text { Pasar archivos de la tableta a la memoria usb o de la memoria usb a la tableta. }\end{array}$ & Ninguna \\
\hline 6 & $\begin{array}{l}\text { Manejo básico de la interfaz externa de la tableta. } \\
\text { Maneja el procesador de texto } \\
\text { Usa el correo electrónico para enviar y recibir correos. } \\
\text { Navega por internet para hacer consultas. } \\
\text { Captura imágenes. } \\
\text { Descarga aplicaciones en la tableta y con ejercicios las aprende a manejar al punto de crear } \\
\text { actividades de enseñanza. }\end{array}$ & $\begin{array}{l}\text { Dificultad editar imágenes o } \\
\text { fotografías. } \\
\text { No maneja la hoja de cálculo. } \\
\text { Se le dificulta pasar archivos } \\
\text { de la tableta a la memoria } \\
\text { usb o de la memoria usb a la } \\
\text { tableta }\end{array}$ \\
\hline
\end{tabular}




\begin{tabular}{|c|c|c|}
\hline Sujeto & Elementos de la tableta que maneja & $\begin{array}{l}\text { Elementos de la } \\
\text { tableta que carece }\end{array}$ \\
\hline 7 & $\begin{array}{l}\text { Manejo de la interfaz externa e interna de la tableta. } \\
\text { Maneja el procesador de texto } \\
\text { y aplicaciones como power point y powtoon para realizar presentaciones para sustentar o dar } \\
\text { a conocer un tema. } \\
\text { Manejo del correo electrónico. } \\
\text { Editar imágenes o fotografías. } \\
\text { Navega por internet para hacer consultas. } \\
\text { Pasar archivos de la tableta a la memoria usb o de la memoria usb a la tableta. }\end{array}$ & Ninguna \\
\hline 8 & $\begin{array}{l}\text { Manejo básico de la interfaz externa de la tableta. } \\
\text { Maneja el procesador de texto } \\
\text { Usa el correo electrónico para enviar y recibir correos. } \\
\text { Navega por internet para hacer consultas. } \\
\text { Captura imágenes. } \\
\text { Descarga aplicaciones en la tableta y con ejercicios las aprende a manejar al punto de crear } \\
\text { actividades de enseñanza. } \\
\text { Pasa archivos de la tableta a la memoria usb o de la memoria usb a la tableta }\end{array}$ & Ninguna \\
\hline 9 & $\begin{array}{l}\text { Manejo básico de la interfaz externa e interna de la tableta. } \\
\text { Maneja el procesador de texto } \\
\text { Usa el correo electrónico para enviar y recibir correos. } \\
\text { Navega por internet para hacer consultas. } \\
\text { Captura imágenes. } \\
\text { Descarga aplicaciones en la tableta y con ejercicios las aprende a manejar al punto de crear } \\
\text { actividades de enseñanza. } \\
\text { Editar imágenes o fotografías. }\end{array}$ & $\begin{array}{l}\text { Se le dificulta pasar archivos } \\
\text { de la tableta a la memoria } \\
\text { usb o de la memoria usb a la } \\
\text { tableta. }\end{array}$ \\
\hline 10 & $\begin{array}{l}\text { Manejo de la interfaz externa e interna de la tableta. } \\
\text { Maneja el procesador de texto, hoja de cálculo y aplicaciones como power point y powtoon } \\
\text { para realizar presentaciones para sustentar o dar a conocer un tema. } \\
\text { Manejo del correo electrónico. } \\
\text { Editar imágenes o fotografías. } \\
\text { Navega por internet para hacer consultas. } \\
\text { Pasar archivos de la tableta a la memoria usb o de la memoria usb a la tableta. } \\
\text { Descarga aplicaciones y crea talleres para trabajar con sus estudiantes. }\end{array}$ & Ninguna \\
\hline
\end{tabular}

La conclusión de esta fase, es uno de los principales logros es que los profesores obtuvieron, fue lograr incorporar las TIC en el aula y apropiarse de ellas sin miedos y con la seguridad de que conocen su manejo, otros cambios significativos fueron el cambio de su metodología de enseñanza, el gusto de los estudiantes por entrar a clase y el fortalecimiento en el trabajo colaborativo y por último se evidencia que las TIC si incide en la GC, generando un aprendizaje significativo, teniendo en cuenta que el profesor elabora con la ayuda de las competencias TIC material digital (guías, mapas conceptuales, editar videos, trabajar cursos virtuales) que comparte con sus estudiantes y compañeros de trabajo, que no solo fortalecen su quehacer profesor si no también su vida personal.

\section{Conclusiones}

La presencia de las TIC en la actualidad, la incorporación en la educación y las aplicaciones de teorías psicológicas basadas preferentemente en perspectivas constructivistas, hacen posible la opción de plantear la formación desde nuevos ángulos y con nuevos enfoques. Asimismo, las TIC permiten generar nuevos ambientes de aprendizaje, con la interacción en los diálogos de saberes entre las disciplinas curriculares al permitir aprender de forma interdisciplinar y abierta. También posibilitan el hecho de "aprender en la multiculturalidad», amplían y multiplican los referentes formativos. Estos nuevos contextos formativos exigen cambios en las competencias y roles del profesor (De Pablos, 2010). El profesor no es el origen único del saber, puesto que «comparte» estas 
competencias con textos, especialistas, expertos, compañeros, personas de otras culturas, redes de conocimiento y bases documentales.

Teniendo en cuenta autores como (Márquez, 2008), (Sánchez, 2012) y (Carneiro, R., Diaz, T. \& Diaz, T., 2009) que hablan de las competencias digitales y su implementación en el aula, se realizó el proceso de cualificación en una Institución Educativa de la Ciudad de Tunja, donde los profesores adquirieron las competencias y las aplicaron, apropiaron e implementaron a su práctica pedagógica en el desarrollo de actividades en el aula de clase.

Asimismo, se logra incorporar el ahorro ecológico y económico que supondría el uso de estos dispositivos como soporte para los actuales libros de texto digitales de algunas editoriales. Por otra parte tanto el profesor como el estudiante pueden acceder a los contenidos de una manera rápida, sencilla y aprovechando todas las opciones multimedia que ofrecen los nuevos formatos en versión digital, tomar notas electrónicas, capturar imágenes y grabar vídeos. Por otra parte, habría que resaltar el papel de las tabletas como recurso tecnológico que permite la creación de una verdadera red de tecnología móvil en el aula de clase, es decir estar en un entorno virtual participando todo el tiempo.

Entre las posibles ventajas de esta tecnología para la clase se puede destacar:

- Trabajar contenidos de las diferentes asignaturas de manera innovadora

- Propiciar la participación activa de los estudiantes en el aula de calase.

- Hacer procesos de realimentación de manera eficiente y de forma oportuna.

- Motivar al estudiante y mantenerlo activo en la atención y el interés por seguir los contenidos.

- Fortalecer el pensamiento crítico y la creatividad, permitiéndole descubrir y participar en la construcción de su conocimiento.

- Apoyar al profesor a averiguar el nivel de comprensión de los contenidos establecidos en el proceso de aprendizaje en tiempo real.

- Generar otros Ambientes de aprendizaje para la presentación de contenidos.

- Monitorear aprendizajes

En cuanto al desarrollo de la investigación que se realizó hasta el momento en la Institución Educativa, se puede concluir que esta institución cuenta con múltiples herramientas tecnológicas dotadas por el Ministerio de Tecnologías de la Información y la Comunicación (MINTIC), pero que por algún tiempo se les dio poco uso.

Se concluyo también que los profesores asumieron y entendieron que los tiempos han cambiado, así como las formas de aprendizaje que tienen los niños y jóvenes, por eso es que ahora según (Prensky, 2001) están los que no conocen nada de la tecnología y son llamados emigrantes digitales, así como los nacidos en la era tecnológica denominados nativos digitales. Y como lo manifestaron los profesores, les fue dejado en la institución herramientas tecnológicas y múltiples aplicaciones educativas, pero en ningún momento les explicaron cómo debían usarlas es decir no hubo una cualificación bien planeada y organizada para poder incorporarlas en el ámbito educativo.

De acuerdo con la cualificación y acompañamiento dado a través de este proyecto investigativo sobre el uso de las TIC y las incidencias de la GC como lo menciona (Gutiérrez y Orozco, 2007) la GC es entendido como una estrategia o un sistema que permite recopilar, organizar, refinar y diseminar el conocimiento de una institución con el fin de satisfacer, por un lado las necesidades de las instituciones educativas y por otro lado las de los profesor y los estudiantes, se aclara que es a partir del conocimiento de los profesores y estudiantes que se construyen caminos y alterativas con herramientas mediadoras como lo son las TIC, que pueden dar solución a una necesidad sentida. De esta forma en la Institución Educativa de la ciudad de Tunja, se concluye que luego de este proceso, hay una actitud objetiva y positiva hacia el uso de las herramientas tecnológicas e informáticas, 
así como también se evidencio que es clara la idea que tienen los profesores sobre el potencial que estas ofrecen en el desarrollo de la enseñanza y aprendizaje, teniendo en cuenta que la sociedad actual lo exige.

Hoy la institución educativa, tiene una visión favorable hacia uso e incorporación de las TIC y es evidente su implementación en algunas actividades representativas, que además recogen las políticas educativas que proponen el cambio y fomento de la innovación, en el quehacer del profesor, como el uso de diferentes instrumentos tecnológicos como las tabletas, el computador y aplicaciones o software que han sido adquirido por medio de Ministerio de Educación Nacional (MEN) para empezar a trabajar proyectos como "geema" ( proyecto de lectura y escritura haciendo uso de recursos digitales), todas esas herramientas que además de ser aceptadas por los estudiantes, son recursos que apoyan el trabajo en el aula.

El uso e incorporación de las TIC en el proceso educativo, influyen en la GC de algunos profesores, no quiere decir que todos acepten la incorporen de las TIC de la misma forma en las aulas. Hay profesores con ciertas barreras que les impide cambiar. Lo que hace la GC es permitir que superen el problema de la división entre el sujeto y el objeto en la medida en que las instituciones educativas no son vistas como mecanismos de procesamientos de información sino como generadores de conocimiento (Nonaka y Takeuchi, 1999). Así, se infiere según (Gutiérrez y Orozco, 2007) que generar conocimiento no es solamente la idea de certeza, sino contempla el papel definitivo de la subjetividad, por lo tanto, el de incertidumbre y la complejidad, dado que el conocimiento es un proceso humano y dinámico. De esta manera se articula el modelo SECl que da cuenta de las actividades que están enmarcadas y que cada proceso dinamiza la generación de conocimiento, como se pudo dar a conocer a los estudiantes y a la institución educativa para apoyar el proceso de aprendizaje y de esta manera influyo las TIC en la GC.

Se concluyó también que el aporte de las fases abordadas permitió gestionar el conocimiento de los profesores mediado por las TIC, para que ellos pudieran gestionar sus procesos de docencia con el fin de empoderarse y actuar ellos mismos, permitiendo que la institución educativa fuera más eficiente y generara mayor calidad educativa al incorporar, apropiar y usar las TIC en el proceso educativo, socializando, externalizando, combinando y haciendo internalización del conocimiento en beneficio de los estudiantes y de la comunidad educativa.

De igual forma fue importante que desde la estrategia de formación y acceso para la apropiación de las TIC, en los diferentes programas que propone el estado, se generaron estrategias o rutas de acción que propiciaron el seguimiento y acompañamiento a los profesores que participaron en las cualificaciones, con el propósito de afianzar su transición hacia un nivel de apropiación de las TIC y que lo proyecto como agente activo capaz de incorporar el uso de estas herramientas para el desarrollo de la practica pedagógica e investigativa en la búsqueda de una educación de calidad.

El uso de las TIC en la práctica profesor, generó un mayor compromiso y visión por fortalecer las competencias tecnológicas, además, es necesario que las instituciones educativas se sensibilicen, apropien y vena la necesidad de incentivar a sus profesores en la vinculación de TIC a sus prácticas pedagógicas, pues no se ha dado la importancia que esto requiere.

Los profesores deben estar en constante articulación entre el MEN, las Secretarias de Educación, las Universidades e Instituciones Educativas encargadas de la gestión de cualificaciones con los profesores y establecer unos objetivos claros y un proceso metodológico coherente, pertinente y adecuado, que permita direccionar la política construida desde lo referente a la formación profesor sea alcanzada en el trabajo con los profesores, ya que éstas se tornan como exigencias con las que debe contar un profesional de la educación, donde todos conozcan lo que las otras entidades ofrecen y no repitan la misma capacitación a la misma población. 


\section{Referencias Bibliográficas}

Arnal, J. A. (1992). Investigación educativa Fundamentos y Metodologías. . (I. 84-335-3725-3., Ed.) Madrid: Editores: Labor.

Carneiro, R. D. (2009). Desafíos de las TIC para el cambio educativo.: OEI -. (F. Santillana, Ed.) Madrid España. Recuperado el 2 de 2020, de http://iec-peru.org/pdf/cambio_educativo.pdf

Corbetta, P. (2007). Metodología y técnicas de investigación social. . . 422 páginas. (Vol. ISBN: 9788448156107.). ESPAÑA: Editorial: McGraw-Hill. 2a edición.

De Pablos, J. (2010). Las competencias informacionales y digitales . Revista De Universidad Y Sociedad Del Conocimiento .

Hernández, S. (2010). (2010). Metodología de la investigación. . (S. D.-H. INTERAMERICANA EDITORES, Ed.) México D.F., México, México: McGRAW-HILL.

Hernández, S. (2012). En Metodología de la Investigación.Estudio de Caso. México, México: Mc Graw Hill. Recuperado el 21 de abril de 2020, de http://metodologia2012.bligoo.cl/media/users/23/1179686/files/332545/04cap_MI5aCD.pdf

Márquez, P. G. (2008). Competencias digitales. Barcelona, España, Barcelona. Recuperado el 30 de 1 de 2020, de http://peremarques.pangea.org/competenciasdigitales.htm\#uno. Competencias digitales

Martínez, P. C. (2006). El Método de Estudio de Caso. Estrategia Metodológica de la Investigación Científica. Revista Pensamiento \& Gestión., 165-193. Recuperado el 24 de 11 de 2019, de http://ciruelo.uninorte.edu.co/pdf/pensamiento_gestion/20/5_El_me

Nonaka, I., \& Takeuchi, H. (1999). La organización creadora de conocimiento. . Mexixo: Oxford University Press.

Peter, B. (2005). Cómo elegir una herramienta de gestión de contenido de un modelo de aprendizaje. Open education europea, 4,5. Obtenido de http://www.elearningeuropa.info/en/node/3157.

Prensky, P. M. (2001). Nativos e Inmigrantes Digitales. Recuperado el 24 de 08 de 2016, de http://www.marcprensky.com/writing/Prensky\%20-\%20Digital\%20Natives,\%20Digital\%20Immigrants\%20\%20Part1.pdf.

Stake, R. E. (2005). Investigación con estudio de casos. Madrid. españa: Ediciones Morata.

Yin, R. K. (1989). Investigation Sobre Estudio De Casos. Diseño Y Métodos. (Vol. Volume 5. ). (S. E. Series., Ed.) New Delhi, London : SAGE Publications International Educational and Professional Publisher.

Esta obra está bajo una Licencia Creative Commons

Attribución-NoCommercial 4.0 International

\section{(cc) EY-NC}

